\title{
Additives Engineered Nonflammable Electrolyte for Safer Potassium Ion Batteries
}

\author{
Gang Liu, Zhen Cao, Lin Zhou, Jiao Zhang, Qujiang Sun, Jang-Yeon Hwang, \\ Luigi Cavallo, LIMIN Wang, Yang-Kook Sun,* and Jun Ming*
}

Potassium ion batteries (KIBs) are attracting great attention as an alternative to lithium-ion batteries due to lower cost and better global sustainability of potassium. However, designing electrolytes compatible with the graphite anode and addressing the safety issue of highly active potassium remains challenging. Herein, a new concept of using additives to engineer nonflammable electrolytes for safer KIBs is introduced. It is discovered that the additives, such as the ethylene sulfate (i.e., DTD), can make the electrolyte of $1.0 \mathrm{M}$ potassium bis(fluorosulfonyl) imide in trimethyl phosphate compat- ible with graphite anode for the first time, without the need of concentrated electrolyte strategies. A new coordination mechanism of additives in the electrolyte is presented. It is shown that the additive can change the $\mathrm{K}^{+}$solvation structure and then determine the interfacial behaviors of $\mathrm{K}^{+}$-solvent on electrode interface, which are critical to affect the graphite performance (i.e., $\mathbf{K}^{+}$-solvent co-insertion, or $\mathbf{K}^{+}$(de-)intercalation). Then, an extremely high potassium storage capability is obtained in graphite electrode for potassium (ion) batteries, particularly the presented high-performance graphite $\mid \mathrm{K}_{0.69} \mathrm{CrO}_{2}$ full battery fully demonstrates the practical application of this newly designed electrolyte. This additive-based strategy can offer more opportunities to tune the electrolyte properties and then serve for the more mobile ion battery system.

\section{Introduction}

Potassium (ion) batteries (KIBs) are of great interest due to the abundant potassium resources, low cost, and good sustainability, which are promising to be alternatives of lithium-ion batteries (LIBs) as the next-generation energy storage systems. ${ }^{[1]}$ This is more attractive as considering the potential of $\mathrm{K}^{+} / \mathrm{K}$ redox couple. This value is exceptionally negative (i.e., $-2.936 \mathrm{~V}$ vs standard hydrogen electrode [SHE]) and even comparable to $-3.040 \mathrm{~V}$ of $\mathrm{Li}^{+} / \mathrm{Li}^{\left[{ }^{2]}\right.}$ enabling the KIBs easier to pursue the higher energy density than that of current sodium-ion battery $\left(-2.714 \mathrm{~V}\right.$ of $\mathrm{Na}^{+} / \mathrm{Na}$, vs SHE). ${ }^{[3]}$ Thus, many kinds of cathodes (e.g., metal layered oxide, ${ }^{[4]}$ polyanionic compound, ${ }^{[5]}$ Prussian blue analogs, ${ }^{[6]}$ organic materials, ${ }^{[7]}$ and metal-organic frameworks ${ }^{[8]}$ ) are being synthesized intensively based on the similar strategies of synthesizing lithium or sodium interacted compounds as reported before. ${ }^{[9]}$ As the counterpart, the anodes, including the carbon-based materials, ${ }^{[10]}$ alloys, ${ }^{[11]}$ metal oxides, ${ }^{[12]}$ and transition metal chalcogenides, ${ }^{[13]}$ are also

G. Liu, L. Zhou, J. Zhang, Dr. Q. Sun, Prof. L. Wang, Prof. J. Ming State Key Laboratory of Rare Earth Resource Utilization Changchun Institute of Applied Chemistry

CAS

Changchun 130022, China

E-mail: jun.ming@ciac.ac.cn

G. Liu, L. Zhou, J. Zhang, Prof. L. Wang, Prof. J. Ming

University of Science and Technology of China

Hefei 230026, China

Dr. Z. Cao, Prof. L. Cavallo

KAUST Catalysis Center

King Abdullah University of Science and Technology (KAUST)

Thuwal 23955-6900, Saudi Arabia

Dr. J.-Y. Hwang, Prof. Y.-K. Sun

Department of Energy Engineering

Hanyang University

Seoul 133-791, Republic of Korea

E-mail: yksun@hanyang.ac.kr being widely developed. Among these anode materials, the graphite is still the most promising anode due to the features of low voltage platform, abundant resources, and environmentfriendly. ${ }^{[10 a]}$ Particularly, the storing mechanism through the metal ions (de-)intercalation (e.g., $\mathrm{Li}^{+}, \mathrm{K}^{+}$) within the graphite can guarantee the safety of KIBs. ${ }^{[14]}$ The safety issue of KIBs is more important because the potassium has much higher activities and more dangerous than that of lithium. ${ }^{[15]}$ Thus, storing the $\mathrm{K}^{+}$within the graphite reversibly is a precondition for the commercialization of the KIBs.

However, the incompatibility of electrolyte and graphite always leads to failure in storing $\mathrm{K}^{+}$, which has become a great challenge in KIBs. ${ }^{[16]}$ This is because the electrolyte decomposition and/or graphite exfoliation (i.e., $\mathrm{K}^{+}$-solventco-insertion) always exist in KIBs, while these problems are hard to overcome. Recently, the strategy of super-high concentrated electrolyte is being proposed to address the incompatibility issue, ${ }^{[17]}$ but the raised-cost and high viscosity need to be addressed in practical applications. Herein, we introduce a new concept of using additives to engineer electrolytes, which can make the 


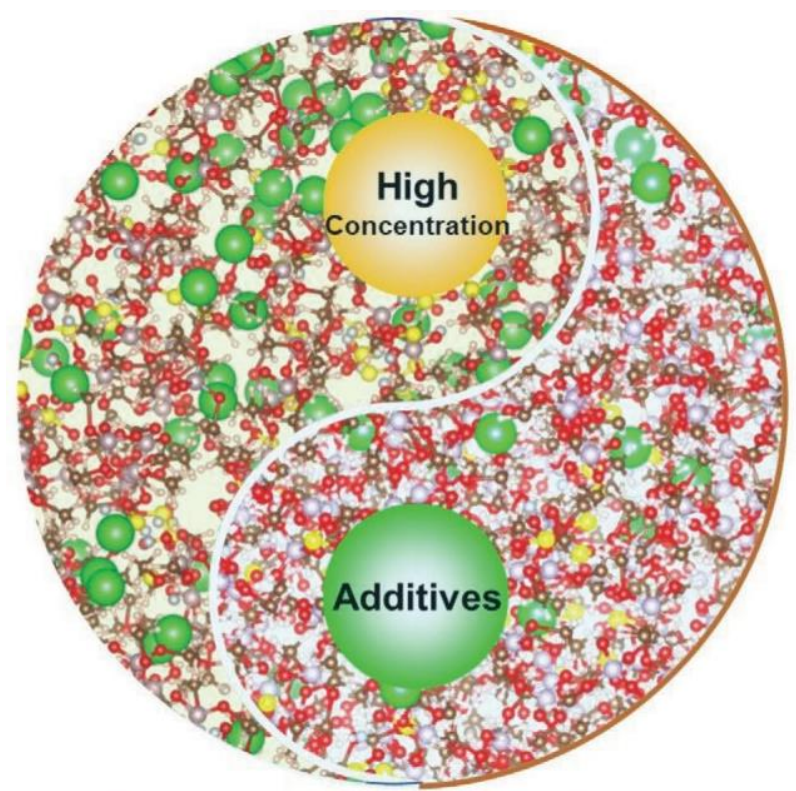

\section{Concentrated Electrolyte vs. Additive Engineered Electrolyte}

Figure 1. Schematic illustration of strategies used for making electrolyte compatible with graphite in potassium (ion) batteries. Concentrated electrolyte strategy (i.e., low solvent/ $\mathrm{K}^{+}$molar ratio around $2-4$ ) versus our presented concept of additive engineered electrolyte (i.e., high solvent $/ \mathrm{K}^{+}$molar ratio around $8-9$ ). The green ball represents the $\mathrm{K}^{+}$cations in the electrolyte.

electrolyte compatible with the graphite, without the need of using the concentrated electrolyte. We discover that the basic unit of electrolyte (i.e., $\mathrm{K}^{+}$solvation structure) can be tuned by the additives (e.g., ethylene sulfate, DTD), then the graphite performance (i.e., $\mathrm{K}^{+}$(de-)intercalation or $\mathrm{K}^{+}$-solvent co-insertion) can be finely controlled. In this way, a new nonflammable electrolyte of $1.0 \mathrm{M}$ potassium bis(fluorosulfonyl) imide (KFSI) in trimethyl phosphate (TMP) compatible with graphite was designed, in which a high potassium storage capability can be achieved. Besides, a safer and high-performance KIBs composed of graphite $\mid \mathrm{K}_{0.69} \mathrm{CrO}_{2}$ was configured for practical applications based on the newly designed electrolyte. This work discovers the important role of additives, which can open a new avenue to make electrolyte compatible with graphite to store the $\mathrm{K}^{+}$in KIBs. We hope this strategy could served for the more mobile ion battery system.

\section{Results and Discussion}

\subsection{Features of Additive Modified Electrolyte}

We present a new strategy of using an additive to engineer electrolyte and then make the electrolyte compatible with the graphite, which might be an alternative strategy for that using concentrated electrolytes (Figure 1). Note that the molar ratio of solvent $/ \mathrm{M}^{+}$(i.e., $\mathrm{M}^{+}=\mathrm{Li}^{+}, \mathrm{Na}^{+}, \mathrm{K}^{+}$, etc.) that calculated by electrolyte concentration is always as low as $1-5$ in the concentrated electrolytes (Tables S1,S2, Supporting Information). In contrast, the additive modified electrolyte can maintain a high solvent $/ \mathrm{M}^{+}$ value around $8-13$ in the most normal electrolyte (e.g., $1.0 \mathrm{M}$ metal-salt based electrolyte, for example, the value is about 13 for the commercial electrolyte of $1.0 \mathrm{M} \mathrm{LiPF}_{6}$ in EC/EMC [v/v, 3/7]), which could also achieve comparable or even better performance. This strategy can reduce the used amount of metal salt and then reduce the cost significantly, and also the viscosity of electrolyte can be decreased for better manipulation of battery productions. In this study, the trimethyl phosphate (TMP) was used as the solvent due to the non-flammable properties, ${ }^{[18]}$ while the ethylene sulfate (DTD, $\mathrm{C}_{2} \mathrm{H}_{4} \mathrm{O}_{4} \mathrm{~S}$ ) was used as the additive because of its capability to form robust solid electrolyte interphase (SEI) and strong coordination capability (i.e., $\mathrm{S} \square \mathrm{O}$ ) in electrolyte (Figure 2a). ${ }^{[19]}$ The great feature of TMP-based electrolyte is the nonflammability, which is hard to be ignited (Figure 2b). In contrast, the traditional EC/DEC-based electrolyte is easy to be ignited (Figure 2c). Besides the non-flammable properties, another series advantages of TMP, such as high dielectric constant $\left(\varepsilon=21.6\right.$ vs $<5.0$ of alkyl linear carbonate solvent), ${ }^{[20]}$ low viscosity (1.3 vs $2.5 \mathrm{mPa}$ s of propylene carbonate), ${ }^{[21]}$ wide operating temperature range $\left(-46-197{ }^{\circ} \mathrm{C}\right)$, high flash point $\left(148^{\circ} \mathrm{C}\right),{ }^{[22]}$ reliable electrochemical stability, and good solubility, guarantee the prospect of the newly designed electrolyte. Thus, the TMP solvent is an ideal nonflammable solvent used in the battery system to address safety concerns.

\subsection{Electrochemical Performance}

The positive effect of DTD additives can be confirmed in the first (dis-)charge curves when the graphite electrode was tested in a potassium half battery (i.e., graphite $\mid \mathrm{K}$ ). A standard (dis-) charge curve with the delivered capacity of $298 \mathrm{mAh} \mathrm{g}^{-1}$ and a much higher initial Coulombic efficiency (i.e., CE) of $86.6 \%$ (vs $67.6 \%$ in blank electrolyte) can be obtained in the electrolyte of $1.0 \mathrm{M}$ KFSI in TMP when $6 \mathrm{wt} \%$ DTD was used (Figure 2d). The typical cyclic voltammetry (CV) curves of graphite in $1.0 \mathrm{M}$ KFSI, $6 \mathrm{wt} \%$ DTD in TMP electrolyte is presented in Figure 2e, in which the good stability and high reversibility in storing $\mathrm{K}^{+}$ can be judged by the overlapped curves since the second cycle. The comparative cycling performance further con-firms the positive effect of DTD. We find that the graphite can deliver an average capacity of $272 \mathrm{mAh} \mathrm{g}^{-1}$ and cycle more than 100 cycles with a high capacity retention of $100.2 \%$ (vs the second cycle) when $6 \mathrm{wt} \%$ DTD was used. In contrast, a severe capacity fading can be observed in the blank electrolyte without using DTD, where the capacity can decay fast from 367 to $5 \mathrm{mAh} \mathrm{g}^{-1}$ within 20 cycles (Figure 2f). A thick SEI covered on the graphite electrode and higher resistance was observed when there is no DTD added in the electrolyte (Figure S1, Supporting Information). The X-ray powder diffraction (XRD) pattern confirms that the fast capacity decay might mainly result from the graphite exfoliation (i.e., caused by the $\mathrm{K}^{+}$-solvent co-insertion). This is because the graphite (002) peak of the graphite electrode was disappeared completely after the 20 cycles (Figure S2, Supporting Information). The graphite demonstrates a high rate capability in such a newly designed electrolyte with $6 \mathrm{wt} \%$ DTD. A high rate capacity of $277,266,254,248,241,235$, and $228 \mathrm{mAh} \mathrm{g}^{-1}$ can be delivered at the rate of $0.2 C, 0.4 C, 0.8 C, 1.2 C, 1.6 C, 2 C$, and $2.4 C$ (where 
a
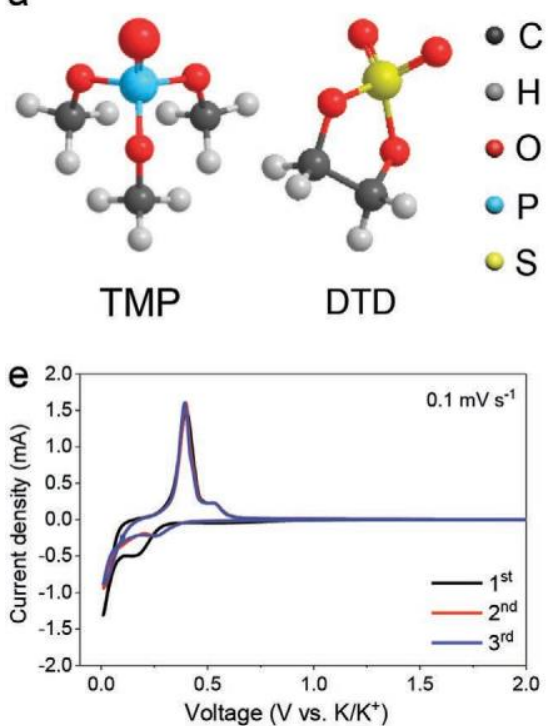

b
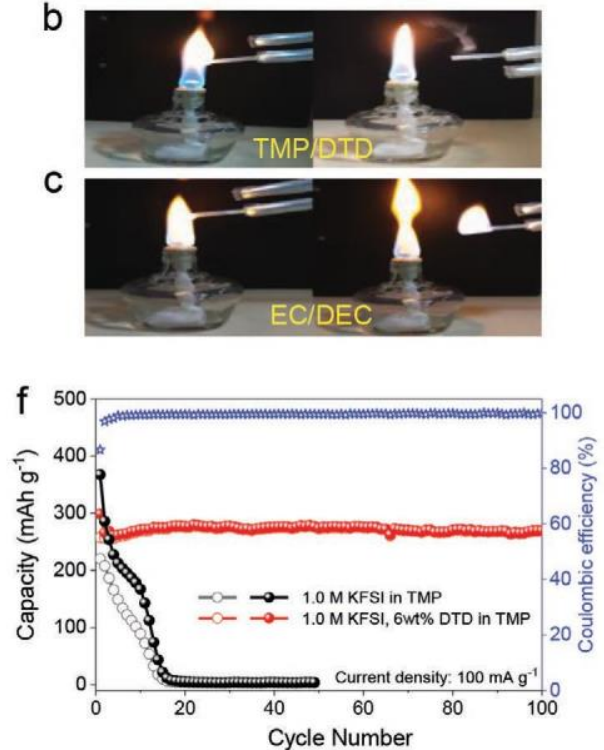
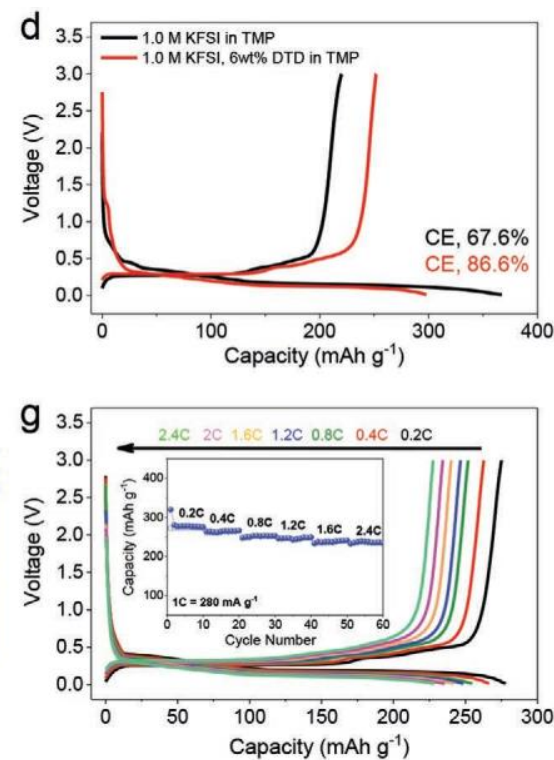

Figure 2. Features of electrolyte and electrochemical performance. a) Molecular structure of TMP and DTD. b,c) Flammability test for TMP and EC-DEC based electrolyte. d) Comparative (dis-)charge curve of graphite electrode in the first cycle in the electrolyte of $1.0 \mathrm{M}$ KFSI in TMP with and without DTD. e) Typical CV of graphite electrode. f) Comparative cycling performance of graphite electrode in the electrolyte of $1.0 \mathrm{M}$ KFSI in TMP with and without DTD. g) Rate capability of graphite electrode in the electrolyte with $6 \mathrm{wt} \%$ DTD.

define $1 C=280 \mathrm{~mA} \mathrm{~g}^{-1}$ ), respectively (Figure $2 \mathrm{~g}$ ). All these results demonstrate the capability of DTD additive which can modify the electrolyte from incompatible to compatible with graphite.

\subsection{Reversible $\mathrm{K}^{+}$(De-)Intercalation Characterizations}

The reversible (de-)intercalation of $\mathrm{K}^{+}$within graphite was further confirmed by the in situ Raman spectrum. We find that
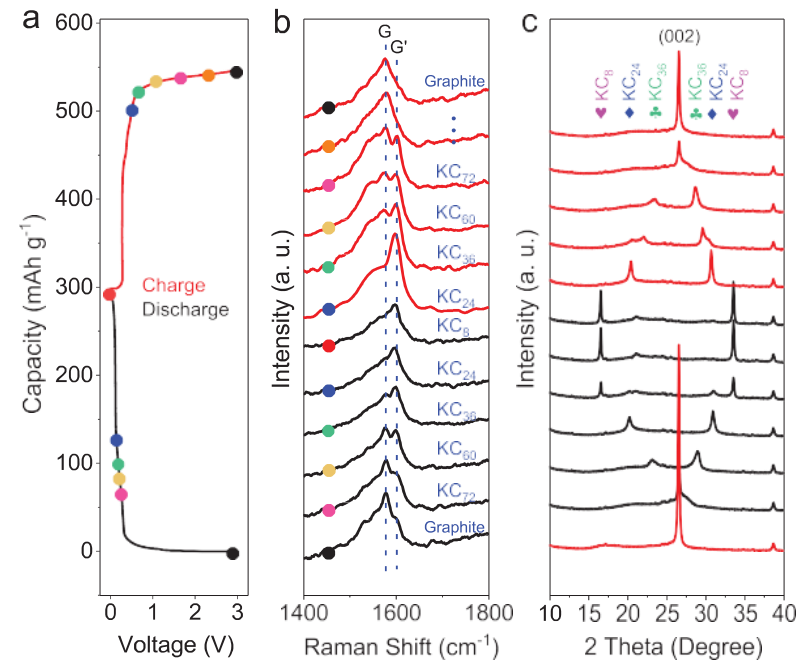

Figure 3. Reversible $\mathrm{K}^{+}$(de-)intercalation characterizations within graphite. a) Galvanostatic (dis-)charge curve in the first cycle. b) In situ Raman spectra of graphite electrode at the different (dis-)charge/charged states, in which the curve with colored circles corresponding the state in the (dis-)charge/charged curves. c) Operando XRD patterns of the graphite electrode at the different (dis-)charged state. the $G$ peak centered at $1582 \mathrm{~cm}^{-1}$ was split and a new peak $\left(G^{\prime}\right)$ around at $1600 \mathrm{~cm}^{-1}$ appeared during the charging pro- cess. This demonstrates that the graphitic layered structure was expanded by the $\mathrm{K}^{+}$intercalation, giving rise to adjacent structure similar to that of single-layered graphene. ${ }^{[23]}$ Besides, the intensity of the new peak $\left(G^{\prime}\right)$ increased gradually and become dominant at the end of discharge due to the formation of the K-graphite intercalation compound. ${ }^{[23]}$ In the following charging process, the new peak $\left(G^{\prime}\right)$ decreased gradually and the $G$ peak recovered when the $\mathrm{K}^{+}$was de-intercalated. The reversible shape variation in the Raman spectrum fully demonstrates the reversible $\mathrm{K}^{+}$(de-)intercalation, in which the phase variation from $\mathrm{C}_{6}$ (graphite), $\mathrm{KC}_{72}, \mathrm{KC}_{60}, \mathrm{KC}_{36}, \mathrm{KC}_{24}$, to $\mathrm{KC}_{8}$, as well as the reversible phase transition in the following charge process, can be observed clearly (Figure 3b). ${ }^{[2]}$ These results are consistent well with the characterizations reported previously. ${ }^{[25]}$

Operando XRD corroborates the reversible $\mathrm{K}^{+}$(de-)intercalation further. We find that the graphitic peak (002) disappeared when the graphite was discharged to the voltage of $0.3-0.2 \mathrm{~V}$ as the $\mathrm{K}^{+}$intercalation, where the new peaks at $22.0^{\circ}$ and $29.4^{\circ}$ confirms the formation of $\mathrm{KC}_{36}$ (i.e., the stage-three $\mathrm{K}$-graphite intercalation compound $[\mathrm{GIC}]$ ) appeared. ${ }^{[26]}$ This result shows that one intercalant layer of potassium was contained in every third gallery. Then, the $\mathrm{KC}_{36}$ transforms to $\mathrm{KC}_{24}$ (i.e., the stagetwo K-GIC) upon further discharge (i.e., $\mathrm{K}^{+}$intercalation), where the new peaks at $20.2^{\circ}$ and $30.6^{\circ}$ are observed. Finally, the phase-pure $\mathrm{KC}_{8}$ (i.e., the stage-one $\mathrm{K}$-GIC) was formed when the graphite was discharged to $0.01 \mathrm{~V}$, as confirmed by the characteristic XRD peaks at $16.4^{\circ}$ and $33.4^{\circ} .{ }^{[10 a]}$ Then, the $\mathrm{K}^{+}$ could be de-intercalated step-by-step in the following charge process, fully demonstrating the reversible $\mathrm{K}^{+}$(de-)intercalation within graphite (Figure 3c). 

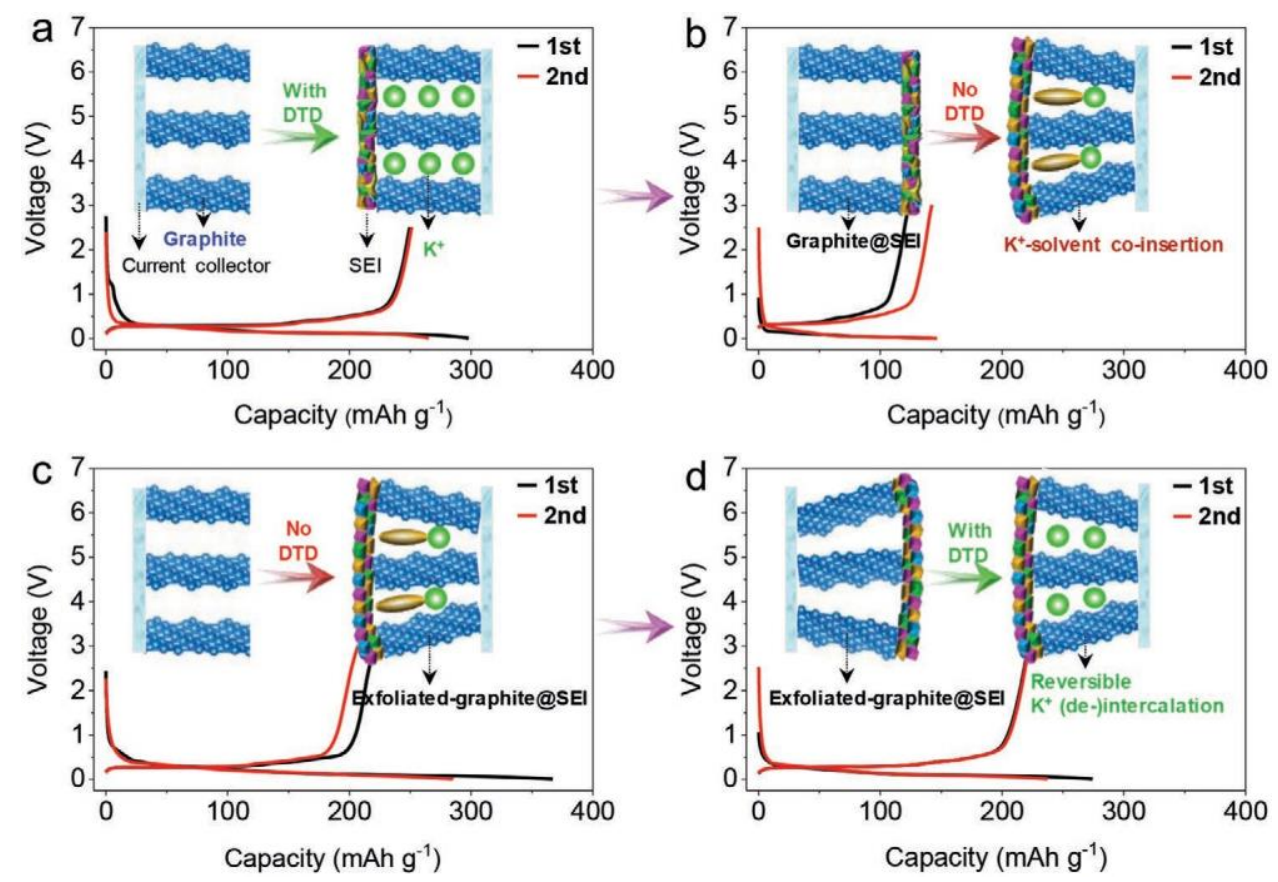

Figure 4. Analysis of the SEI role in the stabilization of the graphite electrode. a) Reversible $\mathrm{K}^{+}$(de-)intercalation within graphite electrode in the electrolyte with 6 wt\% DTD additive; meanwhile the graphite@SEI was formed. b) $\mathrm{K}^{+}$-TMP co-insertion (i.e., graphite exfoliation) was observed when the graphite@SEI formed in (a) was reassembled in a new battery using the electrolyte without DTD additives. c) K+-TMP co-insertion (i.e., graphite exfoliation) within the graphite electrode in the electrolyte without using the DTD additives, where the exfoliated-graphite@SEl can be also formed.

d) Reversible $\mathrm{K}^{+}$(de-)intercalation was observed when the exfoliated-graphite@SEl formed in (c) was reassembled in a new battery using the electrolyte with 6 wt\% DTD additives. Inset is a schematic illustration of the discharge process in different kinds of electrolytes.

\subsection{Analysis of the SEI Role}

We considered the positive effect of DTD that might result from the formed solid electrolyte interphase (i.e., SEI), which may be more robust to suppress the $\mathrm{K}^{+}$-solvent co-insertion when the $6 \mathrm{wt} \%$ DTD was added in the electrolyte (Figure 4a). How- ever, an interesting and unexpected phenomenon we observed in an exchange experiment. For example, we find that the SEI-coated graphite (i.e., graphite@SEI, the fresh graphite cycled in the electrolyte with $6 \mathrm{wt} \%$ DTD in Figure 4a) cannot sustain the cycling performance when the graphite@SEI was reas-sembled in a new battery using the blank electrolyte without the DTD additive (Figure 4b). Note that the initial CE values of graphite@SEI are as high as 95\% at the beginning cycles, which demonstrates that the SEI was indeed formed and exists on the graphite when the graphite electrode was cycled in the electrolyte with $6 \mathrm{wt} \%$ DTD. However, the capacity of the as-formed graphite@SEI electrode decays fast from 140 to $2.5 \mathrm{mAh} \mathrm{g}^{-1}$ after 20 cycles in the electrolyte without $6 \mathrm{wt} \%$ DTD (Figure S3, Supporting Information). This result demonstrates that the formed SEI cannot mitigate the $\mathrm{K}^{+}$-solvent (i.e., $\mathrm{K}^{+}$-TMP) decomposition or $\mathrm{K}^{+}$-solvent co-insertion when the DTD was removed from the electrolyte. This means the compatibility of electrolyte may be dominant to affect the graphite performance compared to the role of SEI. This viewpoint is consistent with our results reported in lithium-ion batteries. ${ }^{[27]}$

A designed converse experiment further confirms our discovery. First, the SEI-coated exfoliated graphite was formed when the graphite electrode was cycled in the blank electrolyte without DTD additives (i.e., exfoliated-graphite@SEI) (Figure 4c). Then, we find that the exfoliated-graphite@SEI can store the $\mathrm{K}^{+}$ reversibly without the $\mathrm{K}^{+}$-solvent co-insertion when the exfoli- atedgraphite@SEI was reassembled in a new battery using the electrolyte with $6 \mathrm{wt} \%$ DTD (Figure 4d). Besides, the capacity of exfoliatedgraphite@SEI electrode can be maintained at $225 \mathrm{mAh} \mathrm{g}^{-1}$, where the low $\mathrm{CE}$ value caused by the exfoliated graphite can be increased from $81 \%$ to $98 \%$ in the electrolyte with $6 \mathrm{wt} \%$ DTD (Figure S3, Supporting Information). This result demonstrates that the exfoliated graphite can store the $\mathrm{K}^{+}$revers- ibly when the compatible electrolyte was used. All these results demonstrate that the SEI can mitigate the electrolyte decompo- sition if the electrolyte is compatible, but it cannot suppress the $\mathrm{K}^{+}$-solvent co-insertion (i.e., graphite exfoliation). In contrast, the electrolyte composition (i.e., $\mathrm{K}^{+}$ solvation structure) is critical to affecting the graphite performance (i.e., $\mathrm{K}^{+}$(de-)intercalation or $\mathrm{K}^{+}$- solvent co-insertion). Thus, the reason for DTD additive making the electrolyte become compatible needs to be explored further.

\subsection{Effect Mechanism of Additives}

The effect of additive on changing the electrolyte properties (i.e., $\mathrm{K}^{+}$solvation structure) was studied further. We used the formula of $\mathrm{K}^{+}$solvation structure (i.e., $\mathrm{K}^{+}$[solvent $]_{x}$ [additive $]_{y}[$ anion] $)$ to describe electrolyte composition according to the molar concentration. ${ }^{[28]}$ This is because the $\mathrm{K}^{+}$solvation structure is the basic unit of electrolyte components, which can reflect the electrolyte properties in detail. The electrolyte of $1.0 \mathrm{M}$ KFSI 


\section{a}

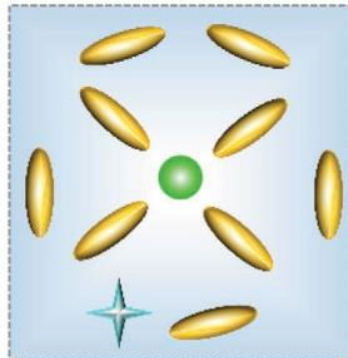

$\mathrm{K}^{+}\left[\mathrm{TMP}_{8.7}\left[\mathrm{FSI}^{-}\right]\right.$

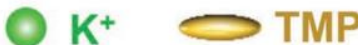

d

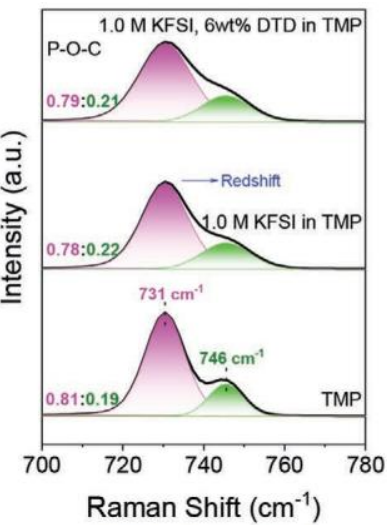

b

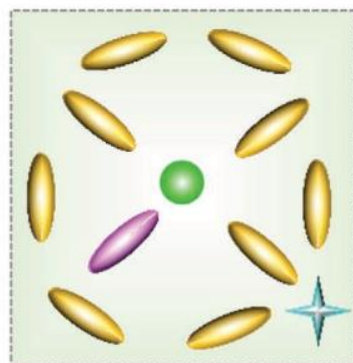

$\mathrm{K}^{+}[\mathrm{TMP}]_{8.7}[\mathrm{DTD}]_{0.58}\left[\mathrm{FSI}^{-}\right]$
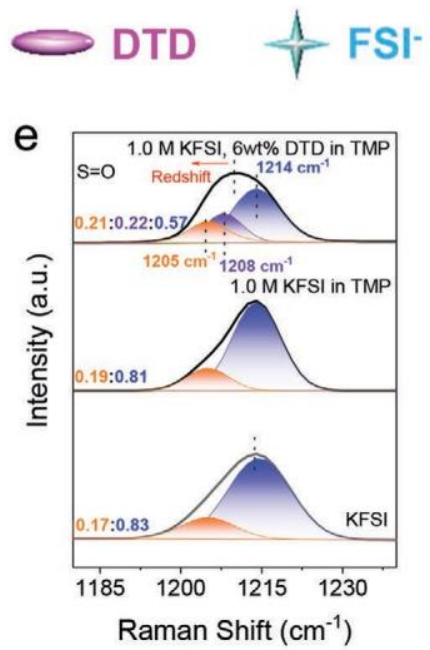

C

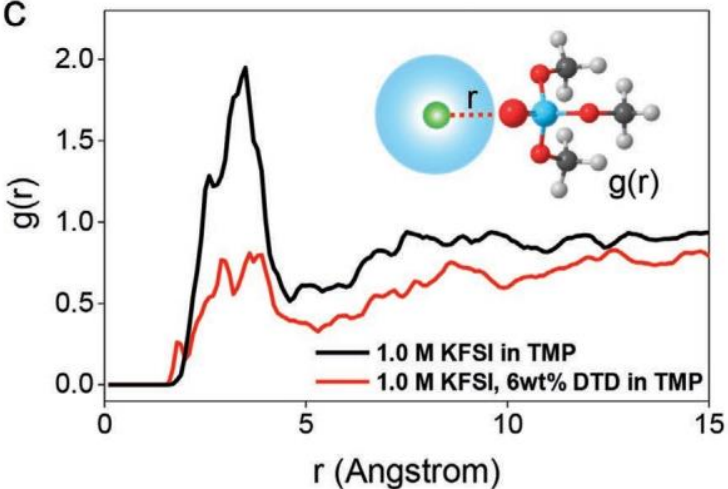

f

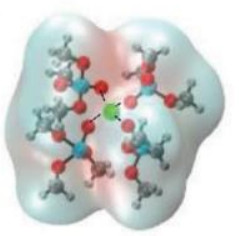

h

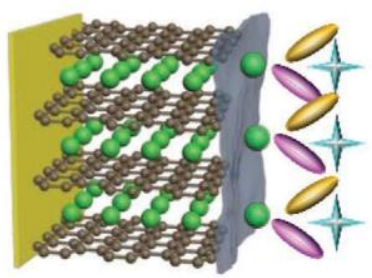

g

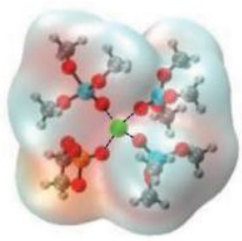

i

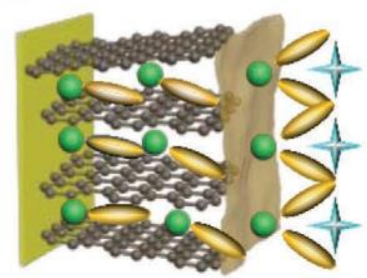

Figure 5. Effect mechanism of additives. a,b) Schematic illustration of molecular interaction between the solvent (TMP), the solute of KFSI, and DTD additives. c) Radial distribution function (RDF) of $\mathrm{K}^{+}$to the oxygen in TMP without and with DTD additives. The inset shows the schematic interactions of $\mathrm{K}^{+}$with oxygen in TMP in and near the first solvation shell (light blue area). Raman spectrum analysis of d) TMP solvent and e) FSI ${ }^{-}$anions in the electrolyte with and without DTD additives. Snapshot of the first solvation shell of $\mathrm{K}^{+} \mathrm{f}$ ) without and $\mathrm{g}$ ) with DTD additives, where the DTD can replace the TMP solvent in the first solvation shell. Different interfacial model and electrochemical behaviors of graphite using different electrolytes of $1.0 \mathrm{M}$ KFSI in TMP h) with and i) without DTD additives.

in TMP with and without $6 \mathrm{wt} \%$ DTD can be described as $\mathrm{K}^{+}[\mathrm{TMP}]_{8.7}[\mathrm{DTD}]_{0.58}\left[\mathrm{FSI}^{-}\right]$and $\mathrm{K}^{+}\left[\mathrm{TMP}_{8.7}\left[\mathrm{FSI}^{-}\right]\right.$, respectively. Note that the coordination number of solvent molecules around the $\mathrm{K}^{+}$ should be $4-6$, herein we use the number of 4 as a simplified case to show the difference in $\mathrm{K}^{+}$solvation structure with and without DTD additives in the electrolyte. Then, a schematic illus- tration of the $\mathrm{K}^{+}$solvation structure was presented in Figure 5a,b. The simulation results show that the frequency of TMP appeared around the $\mathrm{K}^{+}$was reduced when $6 \mathrm{wt} \%$ DTD was added into the electrolyte (Figure 5c). This is rational because the DTD has a stronger coordination capability compared to that of TMP solvent. Thus, the DTD can replace one proportion of TMP solvent and participate in constructing the first solvation shell of central $\mathrm{K}^{+}$ions, thereby changing the $\mathrm{K}^{+}$solvation structure.

The variation of $\mathrm{K}^{+}$solvation structure after adding $6 \mathrm{wt} \%$ DTD was further demonstrated by the Raman analysis. The different molecular behaviors of TMP solvent and KFSI salt can be obtained in detail with and without $6 \mathrm{wt}^{\%} \%$ DTD in the electrolyte. The first, the peaks located at 731 and $746 \mathrm{~cm}^{-1}$ are ascribed to the stretching vibration of the $\mathrm{P} \square \mathrm{O} \square \mathrm{C}$ group in TMP, where the area proportion of peak at the $731 \mathrm{~cm}^{-1}$ decreased from $81 \%$ to $78 \%$ when the KFSI salt was dissolved in TMP. This demonstrates that the TMP coordinates with the $\mathrm{K}^{+}$to form the $\mathrm{K}^{+}$solvation structure (Figure $5 \mathrm{~d}$ ). Then, a blue shift can be observed in the Raman spectrum due to the polarization of TMP solvent molecules induced by $\mathrm{K}^{+}$. While the area proportion of peak located at the $731 \mathrm{~cm}^{-1}$ increases from $78 \%$ to $79 \%$ when $6 \mathrm{wt} \%$ DTD was added into the electrolyte. This means the polarization within TMP molecules induced by $\mathrm{K}^{+}$ was reduced. In other words, this result demonstrates that one proportion of TMP solvents were expelled out from the $\mathrm{K}^{+}$ solvation structure. This conclusion is consistent with the schematic illustration and simulation results (Figure $5 \mathrm{a}-\mathrm{c}$ ).

Besides, the variation of KFSI salt in the electrolyte can be characterized by Raman further. An obvious redshift can be observed for the peaks located about $1210 \mathrm{~cm}^{-1}$, which was ascribed to the decreased stretching vibration of $\mathrm{S} \square \mathrm{O}$ within $\mathrm{FSI}^{-}$(i.e., $\left(\mathrm{FSO}_{2}\right)_{2} \mathrm{~N}^{-}$) anions (Figure 5e). The area proportion of peaks those located at the lower positions of 1205 and $1208 \mathrm{~cm}^{-1}$ (vs $1214 \mathrm{~cm}^{-1}$ ) increased from 17\% (i.e., KFSI), 19\% (i.e., $1.0 \mathrm{M}$ KFSI in TMP) to $43 \%$ when $6 \mathrm{wt} \%$ DTD additive was added into the electrolyte. This means that the interaction between $\mathrm{FSI}^{-}$and $\mathrm{K}^{+}$also become weak when the $6 \mathrm{wt} \%$ DTD was added, further demonstrating the stronger coordination 

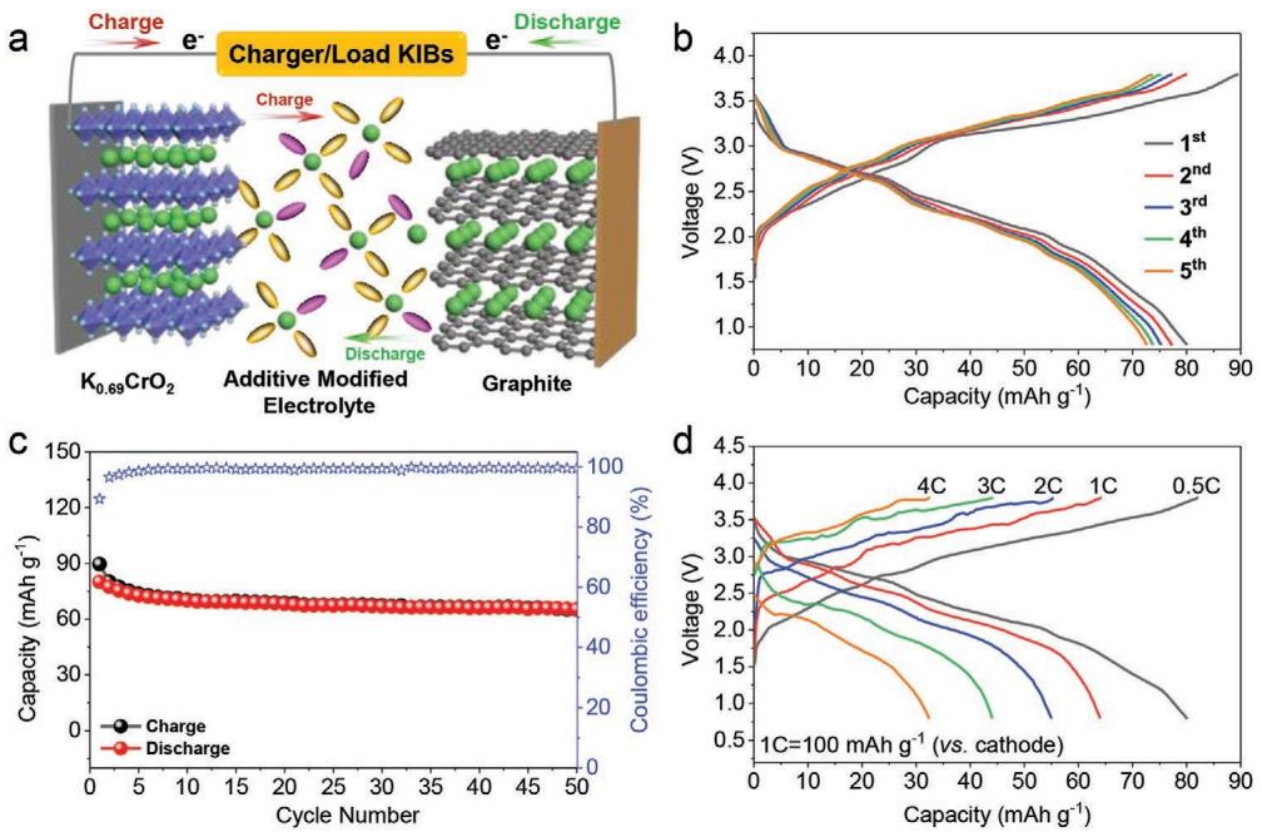

Figure 6. Electrochemical performance of potassium ion full battery. a) Schematic configuration of the $\mathrm{KIBs}$ composed of $\mathrm{K}_{0.69} \mathrm{CrO}_{2}$ cathode and graphite anode. b) Typical voltage versus capacity profiles in the cycling test, c) cycling performance, and d) typical voltage versus capacity profiles in the rate test under a different current density of the KIBs.

capability of DTD in the $\mathrm{K}^{+}$solvation structure. Finally, the snapshot in Figure $5 \mathrm{f}-\mathrm{g}$ shows the simulated $\mathrm{K}^{+}$solvation structure with and without DTD in the electrolyte, in which DTD can be observed in the first solvation shell. In other words, this means the $\mathrm{K}^{+}$-solvent (i.e., $\mathrm{K}^{+}$-TMP) and $\mathrm{K}^{+}$-FSI- interaction can be reduced by the DTD.

Then, we can move our insight from the bulk electrolyte to the electrode interface according to the varied $\mathrm{K}^{+}$solvation structure. The DTD can isolate $\mathrm{K}^{+}$and TMP solvent when the $\mathrm{K}^{+}$ solvation structure was de-solvated step-by-step on the graphite electrode interface. This is because the TMP solvent is easier to be de-solvated due to the weaker coordination capability, where the DTD could be finally de-solvated from the $\mathrm{K}^{+}$. The DTD can keep the TMP solvent slightly far from the $\mathrm{K}^{+}$, thereby suppressing the $\mathrm{K}^{+}$-TMP co-insertion into the graphite (Figure $5 \mathrm{~h}$ ). Here the DTD can isolate the $\mathrm{K}^{+}$and TMP solvent, but the $\mathrm{K}^{+}$DTD cannot be co-inserted due to the low solvation capability of DTD (i.e., solid powers in the room temperature). Thus, the DTD can change the $\mathrm{K}^{+}$solvation structure, determine the interfacial model, and then affect the graphite behaviors (i.e., $\mathrm{K}^{+}$-solvent co-insertion, or $\mathrm{K}^{+}$(de-)intercalation). In contrast, the $\mathrm{K}^{+}$-TMP can appear around the graphite interface if there is no sufficient DTD in the electrolyte, where the $\mathrm{K}^{+}$-TMP is easier to be co-inserted (Figure 5i). This viewpoint was further confirmed when we reduce the amount of DTD additives (e.g., less than $6 \mathrm{wt} \%$ ). For example, we find that the graphite performance cannot be stabilized using $2 \mathrm{wt} \%$ and $4 \mathrm{wt} \%$ DTD in the TMP-based electrolyte (Figure S4a,b, Supporting Information). This is because the amount of DTD is insufficient to compete with the TMP solvent in the $\mathrm{K}^{+}$solvation structure and also on the graphite surface (Figure S4c,d, Supporting Information). Then, the $\mathrm{K}^{+}$-TMP pairs could be co-inserted into the intercalated layer of graphite, leading to the graphite exfoliation and electrolyte decomposition. Besides, other kinds of additives, such as vinylene carbonate (VC) and vinyl ethylene carbonate (VEC), neither can stabilize the graphite performance due to the weaker coordination capability and stability of VC and VEC compared to that of DTD (Figure S5, Supporting Informa-

tion). Thus, we conclude that changing $\mathrm{K}^{+}$-solvent interaction is critical to tune the graphite performance in storing the $\mathrm{K}^{+}$.

This viewpoint can be further confirmed by the model of concentrated electrolyte (Tables S1,S2, Supporting Information). First, the $\mathrm{K}^{+}$solvation structure and the probable interfacial model in concentrated electrolytes were proposed using our theory (Figure S6, Supporting Information). We find that the solvent amount is very limited in the concentrated electrolyte due to the low molar ratio of solvent $/ \mathrm{K}^{+}$, such as the electrolyte of $3.3 \mathrm{M} \mathrm{KFSI}$ in TMP (i.e., $\mathrm{K}^{+}\left[\mathrm{TMP}_{2.6}\left[\mathrm{FSI}^{-}\right]\right)^{[17 \mathrm{a}]}$ and $6.0 \mathrm{M}$ KFSI in DME (i.e., $\mathrm{K}^{+}[\mathrm{DME}]_{1.6}\left[\mathrm{FSI}^{-}\right]$). ${ }^{[17 b]}$ Then, the solvent is hard to be co-inserted into the graphite. This is because the solvent has to be remained in the electrolyte for dissolving the potassium salt (i.e., KFSI). Otherwise, the potassium salt (i.e., KFSI) could be precipitated from the electrolyte if the solvent was co-inserted into the graphite. This is the root cause of why the concentrated electrolyte could be compatible with the graphite. In other words, the increased KFSI concentration (i.e., increased molar of $\mathrm{FSI}^{-}$) decreased the $\mathrm{K}^{+}$-solvent interactions in the electrolyte, then the $\mathrm{K}^{+}$could be de-solvated and intercalated into graphite. In contrast, herein we use the DTD additive to decrease the $\mathrm{K}^{+}$-solvent interactions alternatively, which is more efficient at a lower cost and is easier to manipulate due to the low viscosity. Thus, we confirmed again that the varied $\mathrm{K}^{+}$solvent interaction is the real reason for the reversible $\mathrm{K}^{+}$(de-) intercalation within graphite. 


\subsection{Potassium Full Battery Applications}

The practical application of the newly designed nonflam- mable electrolyte was further verified in the KIB, in which the $\mathrm{K}_{0.69} \mathrm{CrO}_{2}{ }^{[29]}$ was used as the cathode to match the graphite anode (Figure 6a). The graphite was pre-cycled in potassium half battery (i.e., graphite $\mid \mathrm{K})$ to compensate for the irreversibility in the initial cycles. The configured KIB demonstrates a working voltage of $2.25 \mathrm{~V}$, where the typical (dis-) charge curves at $0.5 \mathrm{C}$ $\left(1 \mathrm{C}=100 \mathrm{~mA} \mathrm{~g}^{-1}\right)$ are presented in Figure $6 \mathrm{~b}$. We find that a reversible capacity of $80 \mathrm{mAh} \mathrm{g}^{-1}$ can be delivered and good cycle performance can be maintained, where the Coulombic efficiency can achieve as high as $99.5 \%$ (Figure 6c). The energy density of this as-presented KIB can achieve $178 \mathrm{Wh} \mathrm{kg}^{-1}$ (vs the mass of cathode) as judged by the (dis-)charge curves, thus the estimated practical value might achieve about $70 \mathrm{Wh} \mathrm{kg}^{-1}$ (vs the mass of battery package ${ }^{[30]}$ ) at least in applications. Besides, a robust rate capability can be also observed in such KIBs, where the average capacity of $80,64,55,44$, and $32 \mathrm{mAh} \mathrm{g}^{-1}$ can be delivered at the rate of $0.5 C, 1 C, 2 C, 3 C$, and $4 C\left(1 C=100 \mathrm{~mA} \mathrm{~g}^{-1}\right)$, respectively (Figure 6d). Thus, the reversible $\mathrm{K}^{+}$(de-)intercalation in the KIBs further confirms the feasibility of such newly designed electrolytes for storing $\mathrm{K}^{+}$, where the energy density can be further improved when the higher capacity cathode was developed. ${ }^{[30]}$

\section{Conclusion}

A new concept of using additives to engineer electrolyte was introduced in potassium (ion) batteries, successfully addressing the great issue of electrolyte that incompatibility with graphite for storing $\mathrm{K}^{+}$reversibly. A promising TMP-based nonflammable electrolyte in a normal concentration was designed, and a new coordination mechanism of additives in the electrolyte was presented. We discover that the additive can change the $\mathrm{K}^{+}$ solvation structure and then determine the interfacial behaviors of $\mathrm{K}^{+}$-solvent on electrode interface, which are critical to affect the graphite performance (i.e., $\mathrm{K}^{+}$-solvent co-insertion, or $\mathrm{K}^{+}$(de-)intercalation). Then, high potassium storage capability was obtained in graphite electrode for potassium (ion) bat- teries including the impressive graphite $\mid \mathrm{K}_{0.69} \mathrm{CrO}_{2}$ full $\mathrm{KIBs}$. We believe this work could help us develop a more versatile electrolyte and then serve for the more mobile ion battery system.

\section{Supporting Information}

Supporting Information is available from the Wiley Online Library or from the author.

\section{Acknowledgements}

This work was supported by the National Natural Science Foundation of China $(21978281,21975250)$ and the National Key R\&D Program of China (SQ2017YFE9128100). The authors also thank the Independent Research Project of the State Key Laboratory of Rare Earth Resources Utilization (110005R086), Changchun Institute of Applied Chemistry, Chinese Academy of Sciences. The authors also acknowledge fruitful discussions with the research scientists at Huzhou Kunlun Power Battery Materials Co., Ltd.

\section{Conflict of Interest}

The authors declare no conflict of interest.

\section{Keywords}

additives, nonflammable electrolytes, potassium ion batteries, solid electrolyte interfaces, solvation structures

Received: February 29, 2020 Revised: June 30, 2020

Published online: September 6, 2020

\section{[1] a) X. Wu, D. P. Leonard, X. Ji, CHEM. Mater. 2017, 29, 5031;} b) J. Y. Hwang, S.-T. Myung, Y. K. Sun, Adv. Funct. Mater. 2018, 28, 1802938; c) W.Zhang, Y. Liu, Z. Guo, Sci. Adv. 2019, 5, eaav7412; d) J. Zhang, T. Liu, X. Cheng, M. Xia, R. Zheng, N. Peng, H. Yu, M. Shui, J. Shu, Nano Energy 2019, 60, 340; e) T. Hosaka, K. Kubota, A. S. Hameed, S. Komaba, CHEM. Rev. 2020, https://doi. org/10.1021/acs.chemrev.9b00463.

[2] a) X. Zou, P. Xiong, J. Zhao, J. Hu, Z. Liu, Y.Xu, Phys. CHEM. CHEM. Phys. 2017, 19, 26495;. b) L. Zhou, J. Zhang, Y. Wu, W. Wang, H. Ming, Q. Sun, L. Wang, J. Ming, H. N. Alshareef, Adv. Energy Mater. 2019, 9, 1902194.

[3] a) A. Eftekhari, Z. Jian, X. Ji, ACS Appl. Mater. Interfaces 2017, 9, 4404; b) Y.-S. Hu, Y. Lu, ACS Energy Lett. 2019, 4, 2689.

[4] Y. Hironaka, K. Kubota, S. Komaba, CHEM. COMMUN. 2017, 53, 3693.

[5] K. Chihara, A. Katogi, K. Kubota, S. Komaba, CHEM. COMMUN. 2017, $53,5208$.

[6] A. Eftekhari, J. Power Sources 2004, 126, 221.

[7] Z. Jian, Y.Liang, I. A. Rodríguez-Pérez, Y. Yao, X. Ji, ELECTROCHEM. COMMUN. 2016, 7I, 5.

[8] A. S. Hameed, A. Katogi, K. Kubota, S. Komaba, Adv. Energy Mater. 2019, 9, 1902528.

[9] T. Wang, D. Su, D. Shanmukaraj, T. Rojo, M. Armand, G. Wang, ELECTROCHEM. Energy Rev. 2018, I, 200.

[10] a) Z. Jian, W. Luo, X. Ji, J. AM. CHEM. Soc. 2015, 137, 11566; b) W.Zhang, Z. Cao, W. Wang, E. Alhajji, A. H. Emwas, P. Costa, L. Cavallo, H. N. Alshareef, Angew. CHEM., Int. Ed. 2020, 59, 4448.

[11] a) I. Sultana, M. M. Rahman, Y. Chen, A. M. Glushenkov, Adv. Funct. Mater. 2018, 28, 1703857; b) L. Zhou, Z. Cao, W. Wahyudi, J. Zhang, J. Y. Hwang, Y. Cheng, L. Wang, L. Cavallo, T. Anthopoulos, Y.K. Sun, H. N. Alshareef, J. Ming, ACS Energy Lett. 2020, 5, 766.

[12] S. Dong, Z. Li, Z. Xing, X. Wu, X. Ji, X. Zhang, ACS Appl. Mater. Interfaces 2018, 10, 15542.

[13] B. Tian, W. Tang, K. Leng, Z. Chen, S. J. R. Tan, C. Peng, G.-H. Ning, W. Fu, C. Su, G. W. Zheng, K. P. Loh, ACS Energy Lett. 2017, 2, 1835.

[14] a) W. Luo, J. Wan, B. Ozdemir, W. Bao, Y. Chen, J. Dai, H. Lin, Y. Xu, F. Gu, V. Barone, L. Hu, Nano Lett. 2015, 15, 7671; b) A. P. Cohn, N. Muralidharan, R. Carter, K. Share, L. Oakes, C. L. Pint, J. Mater. CHEM. A 2016, 4, 14954.

[15] J. Xu, Y. Dou, Z. Wei, J. Ma, Y. Deng, Y. Li, H. Liu, S. Dou, Adv. Sci. 2017, 4, 1700146.

[16] J. Zhao, X. Zou, Y. Zhu, Y. Xu, C. Wang, Adv. Funct. Mater. 2016, 26, 8103.

[17] a) G. Zeng, S. Xiong, Y. Qian, L. Ci, J. Feng, J. ELECTROCHEM. Soc. 2019, 166, A117; b) X. Niu, L. Li, J. Qiu, J. Yang, J. Huang, Z. Wu, J. Zou, C. Jiang, J. Gao, L. Wang, Solid State lonics 2019, 34 I, 115050; c) L. Fan, R. Ma, Q. Zhang, X. Jia, B. Lu, Angew. CHEM., Int. Ed. 2019, 58, 10500; d) T. Hosaka, K. Kubota, H. Kojima, S. Komaba, CHEM. COMMUN. 2018, 54, 8387; e) J. Wang, Y. Yamada, K. Sodeyama, E. Watanabe, K. Takada, Y. Tateyama, A. Yamada, Nat. Energy 2018, 
3, 22; f) Z. Zeng, V. Murugesan, K. S. Han, X. Jiang, Y. Cao, L. Xiao, X. Ai, H. Yang, J. G. Zhang, M. L. Sushko, J. Liu, Nat. Energy 2018, 3,674 .

[18] Z. Zeng, X. Jiang, R. Li, D. Yuan, X. Ai, H. Yang, Y. Cao, Adv. Sci. 2016, 3, 1600066.

[19] a) J. Ming, Z. Cao, Y. Wu, W. Wahyudi, W. Wang, X. Guo, L. Cavallo, J. Y. Hwang, A. Shamim, L. J. Li, Y. K. Sun, H. N. Alshareef, ACS Energy Lett. 2019, 4, 2613; b) A. Sano, S. Maruyama, J. Power Sources 2009, 192, 714.

[20] I. N. Daniels, Z. Wang, B. B. Laird, J. Phys. CHEM. C 2017, I2I, 1025.

[21] A. M. Ponrouch, E. Marchante, M. Courty, J. M. Tarascon, M. R. Palacin, Energy Environ. Sci. 2012, 5, 8572.

[22] E. R. Logan, E. M. Tonita, K. L. Gering, J. Li, X. Ma, L. Y. Beaulieu, J. R. Dahn, J. EleCtrocheM. Soc. 2018, 165, A21.

[23] a) L. M. Malard, D. C. Elias, E. S. Alves, M. A. Pimenta, Phys. Rev. Lett. 2008, I0I, 257401; b) A. P. Cohn, K. Share, R. Carter, L. Oakes, C. L. Pint, Nano Lett. 2016, I6, 543; c) R. Baddour-Hadjean, J. P. Pereira-Ramos, CHEM. Rev. 2010, /10, 1278.

[24] a) A. Das, S. Pisana, B. Chakraborty, S. Piscanec, S. K. Saha, U. V. Waghmare, K. S. Novoselov, H. R. Krishnamurthy, A. K. Geim, A. C. Ferrari, A. K. Sood, Nat. Nanotechnol. 2008, 3, 210; b) C. F. Chen, C. H. Park, B. W. Boudouris, J. Horng, B. Geng,
C. Girit, A. Zettl, M. F. Crommie, R. A. Segalman, S. G. Louie, F. Wang, Nature 2011, 47I, 617.

[25] K. Share, A. P. Cohn, R. E. Carter, C. L. Pint, Nanoscale 2016, 8, 16435.

[26] J. C. Chacón-Torres, L. Wirtz, T. Pichler, Phys. Status Solidi B 2014, $251,2337$.

[27] J. Ming, Z. Cao, W. Wahyudi, M. L. Li, P. Kumar, Y.Q. Wu, J. Y. Hwang, M. N. Hedhili, L. Cavallo, Y. K. Sun, L. J. Li, ACS Energy Lett. 2018, 3, 335.

[28] a) J. Zhang, L. Zhou, H. Ming, Y. Wu, W. Wahyudi, Z. Cao, L. Cavallo, L. Wang, J. Ming, CHEM. COMmun. 2019, 55, 5713; b) J. Ming, Z. Cao, Q. Li, W. Wahyudi, W. X. Wang, L. Cavallo, K. J. Park, Y. K. Sun, H. N. Alshareef, ACS Energy Lett. 2019, 4, 1584.

[29] J. Y. Hwang, J. Kim, T. Y. Yu, S. T. Myung, Y. K. Sun, Energy Environ. Sci. 2018, II, 2821.

[30] a) X. Ding, X. Huang, J. Jin, H. Ming, L. Wang, J. Ming, ELECTROCHIM. Acta 2018, 260, 882; b) Y.Zou, Y.Shen, Y.Wu, H. Xue, Y. Guo, G. Liu, L. Wang, J. Ming, CHEM. - Eur. J. 2020, 26, 7930; c) Y. Wu, L. Xie, H. Ming, Y. Guo, J. Y. Hwang, W. Wang, X. He, L. Wang, H. N. Alshareef, Y. K. Sun, J. Ming, ACS Energy Lett. 2020, 5, 807; d) L. Zhou, Z. Cao, W. Wahyudi, J. Zhang, J. Y. Hwang, Y. Cheng, L. Wang, L. Cavallo, T. Anthopoulos, Y. K. Sun, H. N. Alshareef, J. Ming, ACS Energy Lett. 2020, 5, 766. 